This item was submitted to Loughborough's Research Repository by the author.

Items in Figshare are protected by copyright, with all rights reserved, unless otherwise indicated.

\title{
Cost engineering for manufacturing: current and future research
}

PLEASE CITE THE PUBLISHED VERSION

http://dx.doi.org/10.1080/0951192X.2010.542183

PUBLISHER

(c) Taylor and Francis

VERSION

AM (Accepted Manuscript)

LICENCE

CC BY-NC-ND 4.0

REPOSITORY RECORD

Xu, Y., F. Elgh, J.A. Erkoyuncu, O. Bankole, Yee M. Goh, W.M. Cheung, P. Baguley, et al.. 2019. "Cost Engineering for Manufacturing: Current and Future Research". figshare. https://hdl.handle.net/2134/7998. 
This item was submitted to Loughborough's Institutional Repository (https://dspace.lboro.ac.uk/) by the author and is made available under the following Creative Commons Licence conditions.

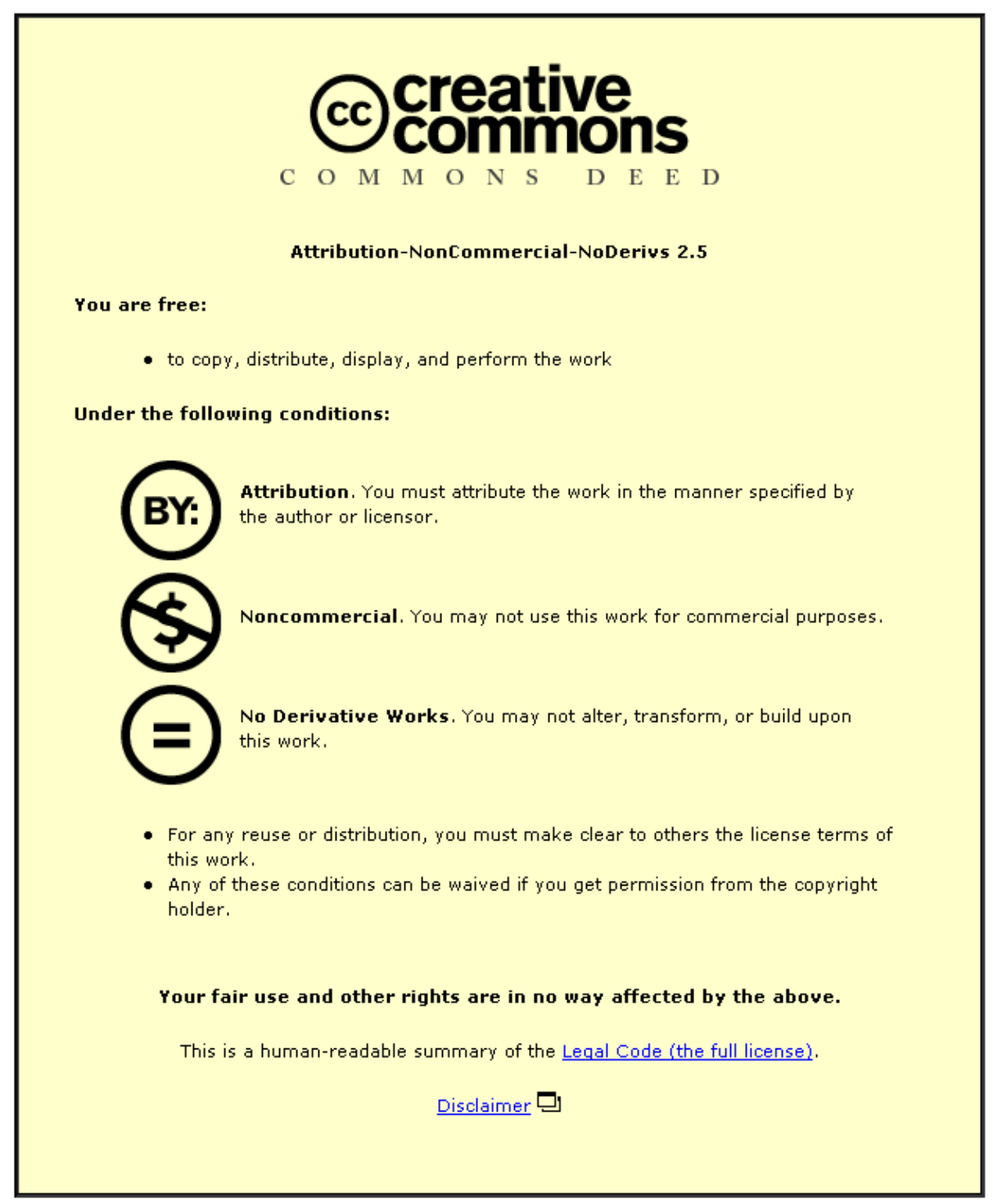

For the full text of this licence, please go to: http://creativecommons.org/licenses/by-nc-nd/2.5/ 


\title{
Cost Engineering for Manufacturing: Current and Future Research
}

Y. $\mathrm{Xu}^{1}$, F. Elgh ${ }^{2}$, J. A. Erkoyuncu ${ }^{1}$, O. Bankole ${ }^{1}$, Y. Goh ${ }^{3}$, W. M. Cheung ${ }^{4}$, P. Baguley ${ }^{1}$, Q.Wang ${ }^{5}$, P. Arundachawat ${ }^{1}$, E. Shehab ${ }^{1}$, L. Newnes ${ }^{6}$, R. Roy ${ }^{1}$

${ }^{1}$ Manufacturing Department, Cranfield University, Cranfield, Bedfordshire, MK43 OAL, United Kingdom

${ }^{2}$ School of Engineering, Jönköping University, 55111, Jönköping, Sweden

${ }^{3}$ Wolfson School of Mechanical and Manufacturing Engineering, Loughborough University, Leicestershire, LE11

3TU, United Kingdom

${ }^{4}$ School of Computing, Engineering and Information Sciences, Northumbria University, Newcastle Upon Tyne, NE1 8ST, United Kingdom

${ }^{5}$ School of Engineering and Computing Sciences, Durham University, Durham, DH1 3LE, United Kingdom

${ }^{6}$ Department of Mechanical Engineering, University of Bath, Bath, BA2 7AY, United Kingdom

\begin{abstract}
The paper aims to identify the scientific challenges and point out future research directions on Cost Engineering. The research areas covered in this paper include: Design Cost; Manufacturing Cost; Operating Cost; Life Cycle Cost; Risk \& Uncertainty management; Affordability Engineering. Collected information at the academic forum on Cost Engineering held at Cranfield University in 2008 and further literature review findings are presented. The forum set the scope of the Cost Engineering research, a brainstorming was held on the forum and literatures were further reviewed to understand the current and future practices in cost engineering. The main benefits of the paper include coverage of the current research on cost engineering from different perspectives and the future research areas on Cost Engineering.
\end{abstract}

Keywords: Cost Engineering, Life Cycle Cost, Risk, Uncertainty, Affordability Engineering

\section{Terminology:}

AACE: Association for the Advancement of Cost Engineering

CAD: Computer Aided Design

CAPP: Computer-aided Process Planning 
CER: Cost Estimation Relationship

CfA: Contracting for Availability

CWTP: Customers Willingness To Pay

DAI: Defence Affordability Index

ERP: Enterprise Resource Planning

HAI: Housing Affordability Index

LCC: Life Cycle Cost

NASA: National Aeronautics and Space Administration

NATO: North Atlantic Treaty Organisation

PSS: product-service systems

TLC: Through-Life Cost

WLC: Whole Life Cost

\section{Introduction}

Cost is a crucial factor which contributes to the success of production and delivery of functional needs, especially within today's highly competitive market. In order to survive and thrive against competition, companies are increasingly required to improve their quality, flexibility, product variety and novelty, while consistently reducing the costs. In short, customers expect higher quality at an ever-decreasing cost. Companies that are unable to provide detailed and meaningful cost estimates at the early development phases have a significantly higher percentage of programs behind schedule and with higher development costs than those that can provide completed cost estimates (Wang \& Potter, 2007).

According to the Association for the Advancement of Cost Engineering (AACE), Cost Engineering is defined as "the area of engineering practice where engineering judgment and experience are used in the application of scientific principles and techniques to problems of cost estimating, cost control, business planning and management science, profitability analysis, project management, and planning and scheduling” (Hollmann, 2006). It is a methodology being used for predicting/forecasting/estimating the cost of a work’s activity or output (Stewart et al., 1995).

Cost Engineering is widely practised in various industry sectors, including manufacturing, aerospace and defence, where a number of approaches have been developed and applied. There are increasing collaboration between academic research and industrial projects. However, scientific challenges of Cost Engineering need for academia to better understand, so that academia can make more valuable contribution to Cost Engineering.

Some researchers reviewed practices of Cost Engineering, e.g. Curran et al (2004) reviewed cost modelling techniques for the aerospace industry, and it is stated that there is no consolidating theoretical approach for Cost Engineering. The paper consequently proposed the genetic causal approach for cost modelling. Roy (2003) reviewed Cost Engineering techniques and the state of art of hardware and software costing. Roy (2008) presented a research 
formalizing cost engineering reasoning process and full service supplier cost modelling. He also pointed out that there is a need for matching the data available in ERP systems against the data requirement for cost engineering. Niazi et al (2006) reviewed different cost estimation techniques and classified them in a hierarchical representation. However, scientific challenges in Cost Engineering have not been well discussed in the above literatures.

Having recognized the importance of understanding the scientific challenges in Cost Engineering, the Academic Forum of Cost Engineering was held at Cranfield University in December 2008. Major researchers from universities in UK (also Europe) attended the forum and discussed important issues. Based on the outputs of this forum and following literature research, this paper is developed aiming to show current research on Cost Engineering, and consequently to identify future research directions. In the followings, Section 2 explains the methodology applied to this paper. Section 3 highlights the background of each research area covered in this paper; Section 4 reviews the current research on Cost Engineering, including Design Cost, Manufacturing Cost, Operating Cost, Life Cycle Cost, Risk \& Uncertainty, and Affordability Engineering. Section 5 identifies and discusses the future research directions on Cost Engineering.

\section{Methodology}

This paper is developed based on the outputs from the Academic Forum of Cost Engineering held at Cranfield University, UK in December 2008, and literature research. Researchers from the University of Bath, Southampton University, Loughborough University, Durham University, and Cranfield University in the United Kingdom and Jönköping University in Sweden attended the forum and presented their research on Design Cost, Manufacturing Cost, Operating Cost, Life Cycle Cost, Risk and Uncertainty, and Affordability Engineering. Literatures were reviewed by following the content analysis method, i.e. specific words or concepts were used in searching/selecting literatures. Figure 1 illustrates the key topics that have been considered in this paper.

Insert Figure 1

In order to capture the current practices in Cost Engineering, the Delphi method (Turoff and Linstone, 2002) was used in some sessions within this paper. This is because some of the information was embedded in individuals and they need to be captured in an iterative way to obtain a reliable consensus of their opinions.

In each selected area, the current research represents the results from the literature review and the work presented at the Academic Forum of Cost Engineering. At the Forum, a brainstorming session was held in order to discuss the 
latest scientific challenges of Cost Engineering. The brainstorming discussions, supplemented by further inputs from each author formed the basis of identifying the future research and scientific challenges of Cost Engineering. The methodology adopted for this paper is shown in Figure 2.

Insert Figure 2

\section{Background of research topics}

This paper is clustered into a variety of research topics in Cost Engineering. This session gives the background about each topic, such as the research contents, and importance etc.

\subsection{Design Cost}

Design Cost is accounted for as a non-recurring cost which includes the cost of defining requirements until the design drawing release in the manufacturing stage (Basir, 2000). The design cost is basically considered as the human effort required to finish a design (Putnam and Myers, 1997). There are two parts in the design cost: the planned cost and unplanned cost (Cho and Eppinger, 2005). The unplanned cost is stochastic in nature and is recognized as “a design rework cost”, and is more difficult to predict. The design rework is defined as unnecessary repetition of design effort due to influences from other design tasks (Arundachawat et al., 2009a) and is considered as negative iteration in product design and development (Ballard, 2000). This unnecessary iteration is a result of design error or design failure due to neglecting something previously known, and moreover the lack of knowledge. The design rework does not cover the design changes due to requirement changes, which is considered as nonmonotonic (Krishnan et al., 1997). It’s important to understand the design rework so that total design effort/cost can be better understood.

\subsection{Manufacturing Cost}

Manufacturing cost has been greatly researched in Cost Engineering. A large number of methods have been developed to enable the calculation of manufacturing cost based on the amount and type of information available (Elgh, 2007; Elgh, 2009). The methods can be classified as intuitive methods, parametric techniques, variant-based models and generative cost estimating (Shebab and Abdalla, 2001). The main approaches for manufacturing cost estimation are variant based costing using the similarities with previously manufactured products, and generative cost estimating where the manufacturing operations are determined (Weustink et al, 2000). Intuitive methods (e.g. the method of successive calculus by Lichtenberg, 2000) are subjective in their nature and rely on the experience of 
the estimators. Parametric methods map characterising product parameters to product manufacturing cost using relations defined by statistical methods. Examples of parametric methods for different manufacturing and assembly processes are given in Boothroyd et al (2002).

\subsection{Operating Cost}

Operating costs constitute a major part of the life cycle cost including the operation (e.g. fuel usage, electricity consumption) and service content (e.g. maintenance, product modification) (Curran et al, 2004). The importance of operating cost had traditionally been partially ignored due to the heavy focus on initial capital costs. The growth in life cycle based contracts promoted the need for robust cost estimates for operating cost (NASA, 2004). A major source of challenge affecting the prediction of operating costs is associated with the limited level of available information (Asiedu and Gu, 1998). This has caused low reliability of estimates and low uptake for practitioners. Furthermore, the life cycle view of asset has created additional challenges by means of risks and uncertainties (Erkoyuncu et al, 2009; Gruneberg et al. 2007).

\subsection{Disposal Cost}

Disposal cost is the cost of disposing end-of-life products. In terms of industrial application, there is much room to bring the disposal segment into the design process of solutions. Furthermore, as interest has grown in this area, various routes to take at this stage have been proposed. For instance, recycling, remanufacturing, reuse and disposal, broadly, are four strategies that can be applied (Asiedu and $\mathrm{Gu}, 1998$ ). Currently, the major focus tends to maximise recycled resources in the disposal phase. Whatever, it is important to select the appropriate strategy at the design stage so that the most efficient manner is incorporated into operations. Disposal cost is becoming ever more important and it starts being considered in many cost estimations.

\subsection{Life Cycle Cost}

Life cycle cost is the total cost over a product's life cycle span (Dhillon, 1981, Xu Y. et al., 2008a), it includes design cost, manufacturing cost, operating cost, and disposal cost. Other terminologies for LCC are WLC (Whole Life Cost) and TLC (Through-Life Cost). Nowadays, companies are more concerned to prepare life cycle cost estimates of a product from its conception until the end of its life. This is emphasised by the shift in industrial business processes which have moved from delivering spares and parts to total care packages through the whole lifetime of a product (Roy et al., 2009).

\subsection{Uncertainty}

Uncertainty can be considered as any deviation from the unachievable ideal of complete deterministic knowledge of the relevant system (Walker et al, 2003). In the context of modelling, uncertainty can be defined as a potential deficiency in any phase of activity of the modelling process that is due to lack of knowledge which causes the 
model-based predictions to differ from reality (AIAA 1998; DeLaurentis 1998). The term contains fuzziness and randomness, while creating doubtfulness and lack of confidence. One important characterisation of uncertainty is whether it is epistemic or aleatory in nature. Aleatory uncertainty, being inherent in the system and cannot be reduced without changing the system, requires the availability of statistical data to fully describe its characteristics. The epistemic uncertainty caused by lack of knowledge is arguably more difficult to quantify and will require fundamentally different strategies (Erkoyuncu et al., 2010a). For instance, uncertainty associated with the future which is unknown including costs associated with future scenarios such as technology obsolescence or changes in legislation.

\subsection{Affordability}

Affordability analysis makes use of the outputs of a LCC to apply investment strategies over the life cycle of equipment. It is a social construct which needs to be conceptualised and operationalised. There are two possibilities for affordability

a) Customer budget is lower than the LCC

b) Customer budget is higher than the LCC

In Cost Engineering, normally knowing cost is not the final aim. More often, it is desired to know where to reduce cost and if customers can afford the product/project cost. Affordability is addressed in this paper to show how cost will be used to assess the customer affordability.

\section{Current Research on Cost Engineering}

\subsection{Design Cost}

Design cost is mainly estimated by considering human effort required for the design phase of a project. Main research in design cost estimation has been conducted to predict the design rework effort. The design rework efforts are estimated based on the fundamental understanding of product design and development, namely vertical planning and horizontal planning. The vertical planning is the planning to coordinate among functions, e.g. design function, prototyping, testing, manufacturing process design, while the horizontal planning is to achieve the integration among interactions of subsystems or components (Clark and Fujimoto, 1989). Research has classified the design tasks as independency, dependency, and interdependency (Yassine et al, 1999) according to the interaction. Interactions among horizontal or vertical direction can cause design rework. Research was conducted to use concurrent engineering approach to reduce design rework. The preliminary information exchanged upstream and downstream is a key factor of design rework. Krishnan et al. (1997) and Terwiesch et al. (2002) studied the design rework caused by exchanging preliminary information. However, both of them simplified design tasks as two types of dependent tasks, i.e. downstream task depends on the change from upstream, while evolution of upstream changes and 
downstream sensitivity to the changes are the key criteria to model design rework. Some other researchers studied the design rework caused by more than two dependent design tasks (Roemer et al. 2000; Chakravarty 2001; and Browning et al., 2002). The design rework problem will be more complex, if it is in the context of multi design tasks interdependency (Arundachawat et al. 2009a).

The later development on design rework effort estimation is focused on simulation and optimisation; however, they are still relied on the fundamental stated above. Furthermore; the key criteria to estimate design rework are considered in more details by separation between probability of design rework occurrence and design rework efforts.

\subsection{Manufacturing Cost}

Manufacturing cost is greatly affected by product design. Product manufacturing cost mainly includes material cost, machining cost, and assembly cost. Materials cost is commonly dominant for many manufactured products (Hendricks, 1989) and can be estimated when the final geometry is defined and the material specified. The machining cost and assembly cost are normally estimated based on the process planning accomplished by production engineers. For every operation defined in a process plan the processing time can be estimated based on the work rate for the resource used to accomplish the operation. When the processing time is known the operation cost can be estimated using the cost rate for the utilization of the resource.

Computer-aided Process Planning (CAPP) systems are used for automating the task of process planning. By using CAPP, the effort required to convert Computer Aided Design (CAD) models into process plans can be reduced. Much research has been devoted to mapping Computer-Aided Design (CAD) model data to a process planning system (Ahmad et al., 2001). There are two general approaches: variant CAPP and generative CAPP (Groover, 2001). Variant CAPP is based on group technology and standard process plans. It often includes manual editing. Generative CAPP utilises decision logic, formulas, manufacturing rules and geometry-based data (e.g. CAD features). In a fully generative CAPP system, there is no need for human assistance or standard plans.

CAPP requires CAD model parsing for the identification of manufacturing features. There are two approaches to identify features in a CAD model for process planning which will determine the manufacturing operations and their sequences: feature recognition and design by feature (McMahon and Brown, 1998). Feature recognition searches the data structure of an existing solid model for combinations of geometric elements and tries to identify pre-defined manufacturing features that correspond to operations. In design by feature, the process of converting features to operations is implemented in the construction of the solid model through the use of standard shape features that correspond to manufacturing operations.

\subsection{Operating Cost}


Operating costs constitute a major part of the life cycle cost. It includes the operation cost (Cost associated with fuel usage, and electricity consumption etc.) and service cost (Costs associated with maintenance, and product modification etc.). The consideration of operation costs has commonly been made in association with service costs. However, cost estimation approaches have varied across operation and service tasks. Table 1 shows the main approaches for estimating operating cost.

\section{Insert Table 1}

\subsubsection{Operation Cost}

The operation cost normally includes direct labour, direct materials, direct expenses, indirect labour, indirect materials and establishment costs. The estimation of these costs is driven by both predicted and actual experience of the performance of similar assets (Woodward, 1997). This necessitates consideration of various cost drivers that contribute to total operational costs. Research to predict operation costs has largely focused on uncertainties that arise over the operating life time span concerning energy costs, fees, staff level and regulatory changes. For instance, Campbell et al., (1982) focus on consideration of supply side uncertainties and their effects on estimating cost in electric utility planning. Boussabaine (2001) focuses on modelling energy costs within a sports facilities context. However, the centre of challenges lies in the availability and reliability of data. Furthermore, it is relatively easy to find data sources providing reliability data, however it is difficult to find data sources for operation data and cost data (Kawauchi and Rausand, 1999).

\subsubsection{Service Cost}

The importance of the service contents has grown across manufacturing industries due to a number of reasons such as diminishing customer budget, the need for increased efficiency and interest in transferring risks (Erkoyuncu et al, 2009). The shift of manufacturers from selling products to services has been studied in the servitization literatures, where product-service systems (PSS) form a specific case (Roy and Cheruvu, 2009). A PSS aims to deliver value by integrating products and services (Baines et al. 2007; Huang, et al. 2009; Goh et al 2010) and it has been formed typically through Contracting for Availability (CfA) in some industries. Service costing considers various activities, e.g. maintenance, repair, asset and operation management service, supply chain management and engineering service and training, that enable or enhance the operational life of given equipment (Asiedu and Gu, 1998). However, most of the literatures are focused towards costing the service associated with stand-alone products (Datta and Roy, 2010). Furthermore, the two main areas of interest in relation to the service phase relates to the prediction of the service life and performance modelling, and cost estimation approaches vary being either deterministic or stochastic methods (Kirkham et al., 2004). This process covers a number of areas including the prediction of the remaining service life of the facility components and the prediction of the rate of their deterioration (NASA, 2004). 
Some of the main objectives that need to be identified and assessed at this stage include (Boussabaine, 2004): survey condition of the existing facility components, assumptions about the remaining service lives of components, updating budget requirement, priority of components updating-critical components, quality of maintenance and replacement components, assumption about time-lag replacement or maintenance delays, the effect of delayed maintenance on budget and deterioration of facility, evaluating the economic viability with a view to disposal.

In service cost estimation, historical data provides guidance in terms of costs and priority of required maintenance, rehabilitation and replacement. However, it is necessary for database cost estimates to be supplemented with expert opinions in order to perform whole life cycle analysis and risk assessment (Roy, 2003). In terms of service cost estimation, interest has been growing recently. A commonly adopted methodology to estimate service costs includes 5 major steps (Brouwer, 2001):

- $\quad$ Well-defined decision problem and clear objectives

- $\quad$ Detailed description of the service(s)

- Identification and classification of resource items and units of resources to deliver service

- $\quad$ Measuring resource consumption

- $\quad$ Placing monetary value on each resource item (goods, activities) and calculating the unit costs of a particular service

\subsection{Disposal Cost}

From a disposal costing perspective this area has been growing recently, as firms have become aware of the significance of the disposal segment of the life cycle. Many researchers have begun to study relevant subjects such as consumer demands for green products, and rising waste disposal costs (Woodward, 1997). However, research in disposal cost estimation is limited mainly due to ad-hoc applications that do not tend to tie-down disposal related responsibilities to any party at the design or operation phases (Boussabaine, 2004). This is mainly due to the lack of information that is available at the bidding stage of contracts. The lack of information particularly centres on the life of an asset where forecasts are challenged by the stochastic nature of equipment life cycle related variables (Asiedu and Gu, 1998). There are five possible determinants of an asset's life expectancy (Woodward, 1997):

- $\quad$ Functional life concentrates on the duration that an asset is needed

- $\quad$ Physical life focuses on the physical ability of an asset to last over a duration

- Technological life refers to the period until technical obsolescence dictates replacement due to the development of a technologically superior alternative

- $\quad$ Economic life relates to the period which obsolescence dictates replacement with a lower cost alternative

- $\quad$ Social and legal life considers the period until human desire or legal requirement dictates replacement

\subsection{Life Cycle Cost}


Extensive research have been undertaken to model LCC on different products (Cheung, et al., 2007). For example Newnes and Mileham (2006) addressed the difficulties of performing LCC on innovative low volume and long life electronic defence systems, and Xu et al adopted the Systems Engineering approach to develop a LCC model for aircraft wing for multi-disciplinary design optimisation (Y. Xu, et al. 2008; Xu Y. et al. 2008).

There are a variety of different approaches for developing life cycle cost models (Stockton et al. 2004; Doyle et al. 2007). These estimation methods vary greatly depending on the type of product being modelled, stage of analysis and the level of detail required. Similarly to the design process where lower level functional requirements are produced through functional decomposition to enable design solutions to be easily developed, it is imperative that cost decomposition is produced. An alternative approach is the concept of function cost (French, 1990), this is based on the principle that many functions can be quantified and the costs associated with a function are often simply related to the quantity or qualities. This approach decomposes the product by function, and quantifies and costs of each function.

Some of the key measures that influence method selection include the relative size of the project, computational aids and skills, user understanding of the technique being applied and availability of useful data (Boussabaine et al. 2004). The consequences of decision making associated with the LCC is often significant, especially efforts to improve the availability of useful data for cost estimating, particularly from the in-service phase where most of the costs encountered within the life cycle will be justifiable.

\subsection{Uncertainty}

There is a significant amount of literature concerning the definition and modelling of uncertainty in a wide range of fields. However, definitions have mainly been driven by “purposes” and "scientific disciplines” (Refsgaard et al., 2007), therefore numerous and varied typologies can be found (Heijungs and Huijbregts 2004; Lloyd and Ries 2007). Table 2 summarised uncertainties in cost data and models typically found.

\section{Insert Table 2}

Despite the significant presence of uncertainties in LCC, traditionally LCC was considered in a deterministic fashion. Recent emphasis in governmental agencies, public and defence sectors on understanding risks associated with LCC estimation has resulted in vast practices of probabilistic methods (Treasury, 2003; Kishk, 2004). In probabilistic methods, uncertainty in the cost data are represented by probability density functions (triangular and normal being most popular) and then propagated through cost models in order to assess the uncertainty in LCC. Analytical and computational methods such as the Monte Carlo simulation are used for uncertainty propagation according to probability theory. However, probabilistic methods although suitable for characterising aleatory uncertainty, may be less useful when statistical data is seriously lacking or when the uncertainty is caused by lack of knowledge (epistemic uncertainty). This drawback has led to the investigation of the possibilistic and fuzzy set 
approaches (Kishk 2004; Oberkampf et al., 2001; Dubois and Prade, 2003). Possibility theory and fuzzy set theory are forms of artificial intelligence, which can be considered to be extensions to probability theory (Dubois and Prade, 2003). These approaches are capable of representing uncertainty with much weaker statements of knowledge and more diverse types of uncertainty (Oberkampf et al., 2001).

There have also been studies that have used deterministic approaches to assess uncertainty (Boussabaine and Kirkham, 2004). Typical approaches in the deterministic approach include sensitivity analysis, net present value and breakeven analysis. To this end, characterisation of epistemic uncertainties is found to be lacking, perhaps due to the difficulty and resources required. Because both types of uncertainty are expected in LCC estimation, it is suggested that a modelling approach that is able to take into account both epistemic and aleatory uncertainty in LCC estimating may be useful. This is particularly driven by the notion that combining aleatory and epistemic uncertainty underestimates the total uncertainty (Oberkampf et al., 2001). Modelling uncertainties tend to be epistemic and can be reduced if further resources are expended to collect evidence, add details to the models, quantify boundary conditions etc. However, to date limited efforts have been observed in industry. Overall, much research has been emphasised on the techniques for modelling uncertainty, however there has been little work on integrating the whole process of uncertainty identification, quantification, response and management strategies (Erkoyuncu et al., 2010b). This implies that uncertainty assessment must guide investment in a holistic manner along the life cycle.

The importance of the in-service phase has grown for manufacturers as customers in many industries such as aerospace, automotive, and construction have adopted an approach that transfers responsibilities to manufacturers (i.e. through equipment availability agreements). The two major aspects that have caused challenges for manufacturers in managing uncertainty within this new context include (1) uncertainties move away from the sale of the equipment towards its utilisation in a bundled and concurrent manner, (2) service contracts require a 'left-shift' of the point-in-time at which uncertainties are addressed at the bidding stage (Erkoyuncu et al., 2009). An important challenge in facilitating this transition towards service orientation is driven by the ability of the customer to transfer data to manufacturers and/or ability of manufacturers to make use of historical data. A summary of the typical issues that arise from using the data are represented in Figure 3 (Durugbo et al., 2009):

\section{Insert Figure 3}

\subsection{Affordability}

The importance of affordability as a research area has led to some effort in providing definitions for affordability because definitions provide a platform for quantitative measures (Milne, 2004). A review by Bankole et al (2009) examined the definitions of affordability across industries. Within the software sector, it is described as the ability to be able to bear the cost of something (Bever and Collofello, 2002). In construction sector, affordability is defined as 
a 'measure of whether housing can be afforded by certain groups of households' (Semple, 2007, Hancock, 1993). In the utilities sector, it is described as the provision of services which can be afforded by customers at different income levels (Milne, 2000). It is 'the share of monthly household income that is spent on utility services such as electricity, heating and water (Frakhauser and Tepic, 2007). Affordability is also defined as the ability to procure a system as the need arises, within a budget, operate at a required performance level and maintain and support it within an allocated life-cycle budget (Kroshl and Pandolfini, 2000). The North Atlantic Treaty Organisation (NATO) described affordability as 'the degree to which the life cycle cost of an acquisition programme is in consonance with the long-range investment and force structure plans of national defence administrations'. It provides the foundation for supporting greater programme stability through the assessment of programme affordability and the determination of affordability constraints (NATO, 2007). Within the aerospace and defence industries, the Network of Excellence in Affordability Engineering (NoE in AE) at Cranfield University defined affordability as 'the degree to which the WLCC of an individual project or program is in consonance with the long range investment capability and evolving customer requirement' (Ray, et al., 2006). Although the definition of affordability is different in different sectors, most definitions are concerned with ensuring there is a balance between total cost of the product or service and the customer's income.

Identifying the factors affecting affordability is another research area. Cost, income or revenue (Bankole et al, 2009), customer value and customer willingness (Anderson et. al., 1993) have been identified as the major factors. Some qualitative factors affecting affordability include risk, world economic climate, requirement, global competition, political situation, legislation, performance related measures, environment, supply chain and quality (Nogal, 2006; Bankole et al., 2010). The impact of each factor on affordability varies from one project to another. This requires a subjective assessment performed on each project, particularly for the qualitative factors.

Another research area is about the measurement of affordability. Mainly affordability is measured by Affordability Index (AI). Two examples given here are Housing Affordability Index (HAI) and the Defence Affordability Index (DAI):

Within the construction sector, HAI is applied to measure the affordability of housing for individual consumers, it is presented as

$$
H A I=\frac{\text { Housing Costs }+ \text { Transportation Costs }}{\text { Income }}
$$

This HAI does not only include the direct cost of housing, but also the additional cost of transport meaning that all costs associated with housing must be considered in determining affordability (Centre for Transit-Oriented Development and Centre for Neighbourhood Technology, 2006).

Within the defence sector, a DAI is defined as below (Nogal, 2006): 


$$
A I=\frac{C A T S}{W L C C}\left(1-\left(\sum_{i=1}^{n} \frac{\left(C_{i}-S_{i}\right)}{S_{i}}\right) \frac{1}{n}\right)
$$

Where,

CATS = what the Customer has Available to Spend/ customer budget

WLCC $=$ Whole life cycle cost

$C_{i}=$ Cost incurred in the ith year

$S_{i}=$ Expected spending ability of the customer for the $i$ th year

$i=$ the years where cost exceeds the expected spending ability of the customer

$n=$ total number of years the cost has exceeded the spending

The DAI is applied under the following conditions:

(i) Total customer budget (CATS) $>0$

(ii) Where individual year's spend is 0 , replace with 1

(iii) If Sum of WLCC < CATS or WLCC = CATS, then only apply CATS/WLCC.

(iv) If there are any violations (individual year's cost > spend) during the project life cycle, then apply full AI.

If the DAI Score $>1$, the project is more affordable; if Score $=1$, project is just affordable and if Score $<1$, the project is unaffordable.

Researchers from Cranfield University refined the quantitative factors and suggested that a different approach should be employed for the qualitative factors. The nature of qualitative factors are very different from quantitative factors, hence factors belonging to two different classes with different attributes should not be assessed in the same way. To assess qualitative factors, the approach proposed includes an assessment based on weights and scores. The weight for each factor assesses the capability of the solution in terms of the factor while the score is an indication of the importance of the factor in assessing affordability. The lower the weighted score the higher the capability and the higher the weighted score, the lower the capability.

\section{Future Research on Cost Engineering}

\subsection{Design and Manufacturing cost}

In design cost research, in order to reduce total effort and lead time in a product design and development, detailed understanding of factors affecting design rework should be further unveiled as attempted previously by Arundachawat et al. (2009b). Also, in-depth study should be conducted to analyse the causes of design rework probability of occurrence and design rework efforts that were not clearly stated previously in literatures. 
In manufacturing cost research, below areas for future research are identified:

- $\quad$ How to bolster the sharing of product and manufacturing information

To enable timely and accurate cost estimation the access to product and manufacturing information is crucial. One approach for sharing and managing information is to set up an information infrastructure based on a shared conceptual model - ontology. Areas for further research are: principles, methods and models supporting the development, use and management of ontology models and ontology based information systems supporting sharing of concepts and information necessary for manufacturing cost estimation. According to Roy (2003), a tool that can be used to predict and estimate the cost with acceptable accuracy requires different types of input as depicted in Figure 4.

\section{Insert Figure 4}

- $\quad$ How to support process planning at detail design stage

To support the process planning at the detailed design stage, two approaches need to be further explored and developed: feature recognition and design by feature. Feature recognition has mainly focused on material removing processes. However, material removing processes require both pre-processing and post-processing. Furthermore, a significant number of products are manufactured by other processes and require assembling operations. Design by feature implies that the manufacturing method is known in advance and that a method for the geometry definition based on the manufacturing operations is used. One area for research would be a more general approach where a limited number of manufacturing alternatives are defined in advance and for each of these a model is created concurrently by a rule base executed automatically as the geometry is defined.

- $\quad$ How to support process planning in the quotation process

To support the process planning and cost estimation in the quotation process with a high level of accuracy requires generative cost estimating, where the manufacturing operations are determined. This implies the recognition of manufacturing features in relation to intended manufacturing resource. One solution could be to further exploit feature recognition as previously described. Another approach is to focus on the manual process planning and develop methods and tools to support the different tasks while increasing the efficiency, shortening the lead time and improving the accuracy of process planning (Elgh, 2008). The further research should address how this can be achieved and how to develop tools to support that. For variant based design the process can be automated (Elgh, 2004). Research has to be conducted to support the development of systems for automated process planning of product variants.

- $\quad$ How to do automatic costing based on CAPP information 
Automated cost estimation of products requires mapping between product design, process plans, utilized resources and costing method (Elgh, 2004). The selection of the costing method has implications on the information required for its completion. Cost estimation based on CAPP information requires necessary information about the process plans and company resources. Therefore, it is of vital importance that the principles and methods for costing are specified, information required are defined, the information sources are traced. In addition, the information should be complete and applicable for its intended use. How to practically do this in an industrial setting is an area for further investigation and research.

\subsection{Operating Cost and Disposal Cost}

In operating and disposal cost research, understanding uncertainties that arise from operations, services and disposal are important and need to be further researched, particularly for bid stage of a project. Within a life cycle cost model it is necessary to acquire approaches that take into account the stochastic nature of operations, services and disposal. For instance, the MoD Strategy of Incremental Acquisition requires a series of equipment upgrades throughout its service life to enhance performance and/or to reduce cost. The challenge and future work lies in the modelling to capture these uncertainties up-front at the bidding stage. Furthermore, all the consequences, including any retraining and requalification will also need to be researched for understanding the cost of such upgrades.

\subsection{Life Cycle Cost}

In LCC research, developing a set of rules that can be used to identify specific sub-systems and components that drive the cost should be researched. For example, the interdependencies between various subsystems might create additional costs and differences in life span and upgrade characteristics are usually difficult to predict and manage.

One of the other challenges in LCC is the lack of research emphasis on the 'in-service' stage, in particular in the transformation from product to product-service system. According to the Operational Availability Handbook (2003), operational availability is the main factor to predict product availability. At the in-service phase of a productservices system, operational availability is used to evaluate operational performance through-out the system life cycle. Therefore, further research is needed to investigate and develop methods to capture the relevant information that drives operational availability and makes it ready at the early design stage to support the prediction of in-service availability.

Also, prediction of low volume systems availability is limited, particularly in methods that used to address the lack of statistically significant data. Therefore a methodology to improve product availability and reliability by predicting spares provisioning needs to be researched, for example, the availability of subsystems and components.

In addition, new techniques need to be further researched to store all the information in a centralised-controlled environment, for example the application of databases. To make use of the data, a navigation-tree technique coupled 
with data query searching techniques to link all the relevant spreadsheets are required. Some technical solutions include:

(i) All the factors that affect the prediction of the 'availability' of a product from the early stage of a design should be identified. For instance, typical factors that drive 'logistic cost' could include transportation, storage, inventory, field support, maintenance etc.

(ii) Derive a new methodology for an integrated costing modelling approach. This integrated approach will focus on 'data acquisition and collection' from different stake holders in the supply chain.

(iii) A generic method of linking proprietary cost estimation systems with the proposed integrated approach.

\section{$5.4 \quad$ Uncertainty}

In the area of uncertainty research, in general, there is a trend of service orientation which is influencing the nature of uncertainties that affect cost estimation for all parties involved; especially the OEMs, who are facing the challenges of understanding the shift in the types of uncertainties that are affecting operation. On one hand, it is necessary to set a framework to capture all or most important uncertainties that affect the LCC estimation in order to maximise effectiveness of decisions that are made early on. On the other hand, it is necessary to understand how uncertainties may vary through the life cycle, in order to associate these with appropriate modelling techniques to the levels of data and knowledge available. In this respect, it is necessary to address the wide scope of uncertainties encountered such that suitable mitigation approaches can be adopted to reduce and manage the effects of uncertainties.

In terms of improving estimation, uncertainty modelling methods that enable consideration of aleatory and epistemic uncertainties separately can be useful. It is emphasised that for addressing aleatory uncertainty, issues associated with availability and quality of data are most critical. Efforts in collecting life cycle information from the in-service phase are particularly important for ensuring meaningful LCC estimation, so this should be addressed in future research. For addressing epistemic uncertainty, there needs to be verification and validation strategies associated with the cost estimating process, in particular, uncertainties in the cost models have not been fully investigated. As the estimated costs may be highly sensitive to these uncertainties, given the importance of decisions associated with the estimated LCC, expenses in these efforts should be justifiable.

\subsection{Affordability Engineering}

In the area of affordability research, it is useful to further identify the link between the customer affordability, manufacturer profitability and supplier sustainability. Also, when considering the qualitative factors which impact affordability, there is a need to define standard measures of weighting to represent the impact of each affordability factor on an individual project. In addition, guidelines could be provided based on the qualitative factors on how to improve the affordability of a project. 
The major factors affecting affordability are the customer budget and LCC. From the customer side, it is important to ensure that the budget is well set in order to cover the LCC of the project. Hence, future research could investigate the process of budget setting. From the manufacturer side, examining possible ways of reducing LCC but maintaining the Customers Willingness To Pay (CWTP) should be researched in order to improve profitability over the life cycle of the project. There is a need to study economic techniques to determine their applicability across different sectors. Also, when considering the qualitative factors which impact affordability, research is need to define standard measures of weighting to represent the impact of each affordability factor on an individual project.

\section{Conclusions}

This paper covers a number of key areas in Cost Engineering, including Design Cost, Manufacturing Cost, Operating Cost, Disposal Cost, Life Cycle Cost, Risk and Uncertainty, Affordability Engineering. In each area, the current research is reviewed and the critical issues are highlighted first, and then the scientific challenges in each area are discussed, and finally some future research topics in each area are discussed. In summary, the current research and knowledge gap in Cost Engineering are:

- In design cost research, main research is on how to predict the design rework effort, including root cause and impact analysis, and design task relationships identification. There is a lack of understanding about the impact of design interrelation on the rework effort.

- In manufacturing cost research, manufacturing cost is estimated based on product and its manufacturing process information. Currently main research is on how to generate CAPP information from product CAD data, including design feature recognition and design by feature. The research in these areas still need to be further researched.

- In operating cost research, the current research is mainly on the uncertainty of operation cost in different application. The research on service cost addresses the shift of manufacturers from selling products to services, service cost modelling, prediction of the service life and performance modelling are currently being researched, and still need to be further researched.

- In disposal cost research, research work includes prediction of the customer needs for green products; and prediction of remaining life of an asset. The research still needs to be developed.

- In LCC research, current research includes performing LCC on innovative low volume and long life products; also the methods of modelling LCC. The method of modelling LCC and incorporating uncertainty analysis still needs to be further researched.

- In uncertainty research, current research includes estimating uncertainty by probabilistic methods; and using the Monte Carlo simulation for uncertainty propagation in LCC model according to probability theory; also using the possibilistic and fuzzy set approaches for uncertainty estimation when data is not 
enough. There is need for a modelling approach that is able to take into accounts both epistemic and aleatory uncertainty in LCC estimating. There is also need for further work on integrating the whole process of uncertainty identification, quantification, response and management strategies.

- In affordability engineering research, current main research is on the definition of affordability engineering, also identifying factors affecting affordability, and the measurement for affordability. Work in these aspects still need to be further researched.

After reviewing current research and finding out the knowledge gap, future research in Cost Engineering are identified in below areas:

- Further understanding the factors impacting design rework;

- Bolstering the sharing of product and manufacturing information;

- Estimate manufacturing cost at early design stage with a high level of accuracy;

- Supporting process planning at the detailed design stage;

- Supporting process planning in the quotation process;

- Implementing automatic costing based on CAPP information;

- Understanding uncertainties throughout the life cycle

- Developing approaches that take into account the stochastic nature of operations, services and disposal.

- Understanding the full scenario of lifecycle and integrate this knowledge into the LCC model.

- Developing new techniques for storing all the relevant information in a centralized-controlled environment for cost analysis.

- Identifying the factors that affect the prediction of 'availability' of a product from the early design stage

- Setting a framework to capture all or most important uncertainties that affect the LCC

- Understanding how uncertainties may vary throughout the life cycle

- Developing uncertainty modelling methods that enable consideration of aleatory and epistemic uncertainties separately

- Developing verification and validation strategies for epistemic uncertainty in cost estimation

- Developing new weights and measures for the qualitative affordability factors.

- Investigating the process of budget setting (especially in the defence sector) to better assess the affordability 
- Identifying the link between the customer affordability and manufacturer profitability to assess the affordability.

\section{Discussion}

The scope of the paper is set by the Academic Cost Engineering Forum held in Cranfield in 2008. As the major universities working on Cost Engineering in UK plus one university form Sweden attended the forum, the scope of this paper covered majority of the research areas of Cost Engineering. On the other hand, not all the researchers from each university attended the forum, and they are not involved in the writing of this paper, so some research areas in Cost Engineering are not included in this paper. For example the obsolescence management in Cost Engineering is not included. Also, the literature review was conducted in the scope setup in the forum, not on all research areas of Cost Engineering. Future research is the representation of knowledge of authors on the development of each research area in Cost Engineering. The authors' knowledge is both from the literature and also the brainstorming discussion in the Academic Cost Engineering Forum.

\section{Acknowledgements}

The authors would like to thank all the attendees in the First Academic Forum of Cost Engineering in UK for presenting the research work, and discussing the scientific challenges of Cost Engineering.

\section{References}

Ahmad, N. et al., 2001. Current Trend in Computer Aided Process Planning. Proceedings of the 7th Annual Paper Meet and 2nd International Conference, October 25-27, 2001, Dhaka, Bangladesh .

Al-Churaiz, Y. and Enshassi, A., 2005. Ability and willingness to pay for water supply service in the GAZA strip. Building and Environment, 40, 1093-1102.

American Institute of Aeronautics and Astronautics (AIAA), 1998. Guide for the Verification and Validation of Computational Fluid Dynamics Simulations, AIAA G 077-1998.

Anderson, J.C. et al., 1993. Customer Value Assessment in Business Markets: A State-of-Practice Study. Journal of Business to Business Marketing 1(1), 3-30 
Arundachawat, P. et al., 2009a. Design Rework Prediction in Concurrent Design Environment: Current

Trends and Future Research Directions, Proceedings of the $1^{\text {st }}$ CIRP IPSS Conference, Cranfield University, Cranfield UK.

Arundachawat P, et al., 2009b. An Analogy Based Estimation Framework for Design Rework Efforts. 16th ISPE International Conference on Concurrent Engineering (CE2009), July 20-24 ${ }^{\text {th }}$, Taiwan, 203-211

Asiedu, Y. and Gu P., 1998. Product life cycle cost analysis: state of the art review. International Journal of Production Research, 36(4), 883 - 908.

Baines, T. et al., 2007. State-of-the-art in product-service systems. Proceedings of the Institution of Mechanical Engineers, Part B: Journal of Engineering Manufacture, 221(10), 1543-1552.

Bashire, H. A., 2000. Models for Estimating Design Effort. Thesis (PhD). McGill University, Canada.

Bankole, O.O. et al., 2009. Current Practice in Affordability Assessment of Product-Service Systems within the Aerospace and Defence industries. Proceedings of the $1^{\text {st }}$ CIRP IPSS Conference, Cranfield University, 230-237.

Bever, B. and Collofello, J., 2002. An investigation of techniques for addressing software affordability. Aerospace Conference Proceedings, 2002. IEEE 5:5-2577 - 5-2585.

Boothroyd, G. et al., 2002. Product Design for Manufacture and Assembly. Marcel Dekker, New York, USA.

Boussabaine, A. H., 2001. A comparative approach for modelling the cost of energy in sport facilities. ABI/INFORM Global, 19, 194-203.

Boussabaine A. and Kirkham R., 2004. Whole Life-cycle Costing: Risk and risk responses. Blackwell Publishing, 1st Edition, 56-81.

Brouwer W. et al., 2001. Costing in economic evaluations” In: Drummond M, McGuire A (eds) Economic evaluation in health care: Merging theory with practice. Oxford University Press, 68-93.

Browning, T. and Eppinger, S. D., 2002. Modelling Impacts of Process Architecture on Cost and Schedule Risk in Product Development. IEEE Transaction on Engineering Management, 49(4), 428-441.

Campbell K.W. et al., 1982. Estimating Operational Costs in an Electric Utility. The International Journal of Management Science, 10(4), 373-382.

Centre for Transit-Oriented Development and Centre for Neighbourhood Technology, 2006. The Affordability Index: A New Tool for Measuring the True Affordability of a Housing Choice [online]. The Urban Markets 
Initiative, Market

Innovation

Brief.

Available

at:

http://www.brookings.edu/reports/2006/01_affordability_index.aspx [Accessed 20th January 2010].

Chakravarty, A., 2001. Overlapping Design and Build Cycles in Product Development. European Journal of Operation Research, 134, 392-424.

Cheung, W.M., et al., 2007. A Study of Life Cycle Costing in the Perspectives of Research and Commercial Applications in the 21st Century. Proceedings of the ASME International Design Engineering Technical Conferences \& Computers and Information in Engineering Conference, IDETC/CIE 2007, Las Vegas, Nevada, USA, DETC2007-34425.

Cho, S. and Eppinger, S.D., 2005. A simulation-based process model for managing complex design projects. IEEE Transactions on Engineering Management, 52(3), 316- 328.

Clark, K. B. and Fujimoto, T., 1989. Lead Time in Automobile Product Development Explaining the Japanese Advantage. Journal of Engineering and Technology Management, 6, 25-60.

Curran, R., et al., 2004. Review of aerospace engineering cost modelling: The genetic causal approach, Progress in Aerospace Sciences, 40(8), 487-534.

Datta, P. and Roy, R., 2010. Cost modelling techniques for availability type service support contracts: A literature review and empirical study. Submitted to CIRP Journal of Manufacturing Science and Technology,

DeLaurentis, D. A., 1998. A Probabilistic Approach to Aircraft Design Emphasizing Stability and Control Uncertainties. Thesis (PhD) Georgia Tech, Atlanta, USA,

Dhillon B.S., 1981. Life cycle cost: A survey. Microelectronic Reliability, 21(4), 495-511

Doyle, J. \& Wang, Q., 2007. Product life cycle process analysis. International Conference on Product Life Cycle Management: Assessing the Industrial Relevance, 11-13 July, 2007, Kilometro rosso Italy, 61-70.

Dubois, D. and Prade, H., 2003. Fuzzy set and possibility theory based methods in artificial intelligence. Artificial Intelligence, 148, 1-9.

Durugbo, C. et al., 2009. Data uncertainty assessment and information flow analysis for Product-Service Systems in a library case study. International Journal of Services Operations and Informatics (IJSOI). In Press.

French, M. J., 1990. Function Costing: potential aid to designers. Journal of Engineering Design, 47-53. 
Elgh, F., 2004. A Generic Framework for Automated Cost Evaluation of Product Variants and Fabrication Plants. Proceedings of DETC2004: ASME Design Engineering Technical Conferences and Computers and Information in Engineering Conference, September 28 - October 2, 2004, Salt Lake City, Utah, USA, 823-832.

Elgh, F. and Cederfeldt, M., 2007. Concurrent Cost Estimation as a Tool for Enhanced Producibility - System Development and Applicability for Producibility Studies. Journal of Production Economics, 109(1-2), 12-26.

Elgh, F., 2008. Enhancing the Efficiency and Accuracy in the Quotation Process of Turned Components, Proceedings of DETC2004: ASME Design Engineering Technical Conferences and Computers and Information in Engineering Conference, August 3 - 6, 2008, New York, USA, 247-256.

Elgh, F. and Sunnersjö, S., 2009. Collaborative Engineering for Enhanced Producibility by Ontology-based Integration of Design and Production, In: Ned Kock (Ed.) Virtual Team Leadership and Collaborative Engineering Advancements: Contemporary Issues and Implications (Advances in e-Collaboration Series: Volume 3), IGI Global, 166-187.

Erkoyuncu, J. A. et al., 2009. Uncertainty challenges in service cost estimation for product- service systems in the aerospace and defence industries, Proceedings of the $1^{\text {st }}$ CIRP IPSS Conference, Cranfield University, Cranfield, 200-206.

Erkoyuncu, J. A. et al., 2010a. Understanding service uncertainties in Industrial Product- Service System cost estimation. Journal of Advanced Manufacturing Technology, In Press.

Erkoyuncu, J. A. et al., 2010b. Managing uncertainty in service cost estimation for Product Service Systems. Submitted to IMechE Part B.

French, M. J., 1990, Journal of Engineering Design - Function Costing: potential aid to designers, 47-53.

Goh, Y. M., Newnes, L., Mileham, A., McMahon, C. and Saravi, M., Uncertainty in Through Life Costing - Review and Perspectives, IEEE Transactions Engineering Management. Accepted November 2009

Hancock, K. E., 1993. Can Pay? Won't Pay? or Economic Principles of Affordability. Urban Studies, 30 (1), $127-$ 145.

Heijungs, R. and Huijbregts M. A., 2004. A Review of Approaches to Treat Uncertainty in LCA. Proc. IEMSS. Osnabruck, 1-8.

Hendricks, J.A., 1989. Accounting for automation. Mechanical Engineering, 111(2), 64-69. 
Hollmann, J.K., 2006. Required skills and knowledge of cost engineering, AACE International Recommended Practice No., 11R-88, 1-22.

Huang, X.X., Newnes L., Parry, G., A critique of product and service based systems" Proceedings of ICMRC, 810th September 2009, WMG, University of Warwick, England

Jian, L. and Hong-fu, Z., 2004. The predictive models of maintenance costs for a civil airplane. Proc. IMechE, 218, 347-351.

Kawauchi Y. and Rausand M., 1999. Life Cycle Cost (LCC) analysis in oil and chemical process industries [online]. Available from: http://www.ntnu.no/ross/reports/lcc.pdf [Accessed 12 March 2009].

Kimita, K., et al., 2009. A customer value model for sustainable service design. CIRP Journal of manufacturing science and technology, 1, 254-261.

Kirkham R.J. et al., 2004. EUROLIFEFORM: An integrated probabilistic whole life cycle cost and performance model for buildings and civil infrastructure [online]. The international construction research conference of the Royal Institution of Chartered Surveyors, COBRA 2004, 7-8 September Leeds Metropolitan University. Available from: http://www.rics.org/site/download_feed.aspx?fileID=2482\&fileExtension=PDF [Accessed 12 December 2009].

Kirk S.J. and Dell’Isolsa A.J., 1995. Life cycle costing for design professionals. McGraw-Hill, New York, 25-54.

Kishk, M., 2004. Combining various facets of uncertainty in whole-life cost modeling. Construction Management and Economics 22(4), 429 - 435.

Krishnan, V. et al., 1997. A Model-Based Framework to Overlap Product Development Activities, Journal of Management Science, 43(4), 437-451.

Kroshl, W.M. and Pandolfini, P.P., 2000. Affordability Analysis for DARPA Programs. Johns Hopkins APL Technical Digest, 21(3), 438 - 447.

Kumar, V., Shirodkar, P.S., Camelio, J.A., \& Sutherland, J. W., 2007, Value Flow Characterization During Product Lifecycle to Assist in Recovery Decisions, International Journal of Production Research, 45(18): 4555-4572.

Lichtenberg, S., 2000. Proactive Management of Uncertainty Using the Successive Principle. Polyteknisk Press, Copenhagen, Denmark.

Lloyd, S. M. and R. Ries, 2007. Characterizing, Propagating, and Analyzing Uncertainty in Life-Cycle Assessment: A Survey of Quantitative Approaches. Journal of Industrial Ecology 11(1), 161-179. 
Milne, C., 2000, Affordability of basic telephone service: an income distribution approach. Telecommunications Policy 24, 907-927.

Milne, C., 2004, Towards defining and measuring affordability of utilities - a discussion paper. [online]. PUAF Communications discussion paper. Available from: http://www.antelope.org.uk/affordability/ PUAF_affordability_discussion_paper.pdf [Accessed 24th April, 2009].

NASA, 2004, Cost Estimating Handbook, [Online] Accessed from; http:/www.ceh.nasa.gov/webhelpfiles/ Cost_Estimating_Handbook_NASA_2004.htm

NATO, 2007. RTO Technical Report, [online]. NATO, Annex D, Pg D1. Available from: http://www.rta.nato.int/pubs/rdp.asp?RDP=RTO-TR-SAS-054 [Accessed 8th July 2009].

Newnes, L.B. and Mileham, A.R., 2006. A Proposed Method for Cost estimating for Low Volume Infrequent Electronic Products. Proceedings of the 13th International Conference on Concurrent Engineering (ISPE CE 2006), Antibes, France, IOS Press, ISBN 1-58603-651-3, 699-706.

Niazi, A. et al., 2006. Product Cost Estimation: Technique Classification and Methodology Review. Journal of Manufacturing Science and Engineering, 128, 563-575.

Nogal Miguel, S., 2006. Development for framework for Affordability Engineering Measurement, Thesis (MSc) Cranfield University, Cranfield, UK.

Oberkampf, W. and Helton, J., 2001. Mathematical Representation of Uncertainty. Non-Deterministic Approaches Forum, AIAA, Seattle WA, April 16-19, AIAA-2001-1645.

Ray, A. et al., 2006. Developing a Framework for Affordability Engineering. The $4^{\text {th }}$ International Conference on Manufacturing Research (ICMR 2006), Liverpool John Moores University, $5^{\text {th }}-7^{\text {th }}$ September 2006, 11-16.

Refsgaard J. C. et al., 2007. Uncertainty in the environmental modeling process-A framework and guidance. Environmental Modelling \&Software, 22(11), pp. 1543-1556.

Roemer, T. et al., 2000. Time-Cost Tradeoffs in Overlapped Product Development. Journal of Operation Research, 48(6), 860-865.

Roy, R., 2003. Cost Engineering: Why, What and How? Decision Engineering Report Series, Cranfield University, ISBN 1-861940-96-3.

Roy, R. and Cheruvu, K.S, 2009. A competitive framework for industrial product service systems, Int. J. Internet Manufacturing and Services, 2009, 2(1): 4-29. 
Roy, R., et al., 2009. Cost of Industrial Product-Service Systems (IPS ${ }^{2}$ ), Keynote paper, 16th CIRP International Conference on Life Cycle Engineering.

Semple, J., 2007. Review into Affordability Housing Final Report [online]. Department for Social Development in Northern Ireland. Available from: http://www.dsdni.gov.uk/affordable_housing_final.pdf [Accessed 8th July, 2008].

Stewart, R. et al., 1995. Cost Estimator's Reference Manual. 2nd ed., Wiley Interscience.

Shehab, E.M. and Abdalla, H.S., 2001. Manufacturing Cost Modelling for Concurrent Product Development. Robotics and Computer Integrated Manufacturing, 17(4), 341-353.

Stockton, D. J. and Wang, Q., 2004. Developing Cost Models by Advanced Modelling Technology, Proceedings of the ImechE Part B: Journal of Engineering Manufacture, 218(2), 213-224.

Terwiesch, C. H. et al., 2002. Exchanging Preliminary Information in Concurrent Engineering: Alternative Coordination Strategies”, Journal of Organization Science, 13(4), 402-421.

Treasury, 2003. The Green Book Appraisal and Evaluation in Central Government. London.

Turoff, M. and Linstone, H., 2002. The Delphi Method: Techniques and Applications [online]. New Jersey Institute of Technology, Newark, USA. Available from: http://is.njit.edu/pubs/delphibook/ [Accessed October 2009].

Walker, W.E., et al., 2003. Defining Uncertainty: A conceptual basis for uncertainty management in model based decision support” Integrated Assessment. 4(1), pp. 5-17.Rreferences

Wang, Q. \& Potter, N., 2007. Incorporating life cycle costing in early product design, International Journal of Advanced Manufcaturing Systems, 10(1), 33-40.

Weustink, I.F. et al., 2000. A Generic Framework for Cost Estimation and Cost Control in Product Design. Journal of Materials Processing Technology, 130(1), 141-148.

Woodward, D.G., 1997. Life cycle costing-theory information acquisition and application. International Journal of Project Management, 15(6), 335-344.

Xu, Y. et al., 2008. Object-Oriented Systems Engineering Approach for Modeling Life Cycle Cost of Aircraft Wing”, the 46th AIAA Aerospace Sciences Meeting and Exhibit, January, Reno, Nevada, USA

Xu, Y., Wang, J., Tan, X., Raghunathan, S., Doherty, J., and Gore, D.. A Generic Life Cycle Cost Modeling Approach for Aircraft System”, Proceedings of the 15th ISPE International Conference on Concurrent Engineering (CE2008), 251-258. 
Yassine, A. A. et al., 1999. A Decision Analytic Framework for Evaluating Concurrent Engineering. IEEE

Transactions on Engineering Management. 46(2), 144-157. 


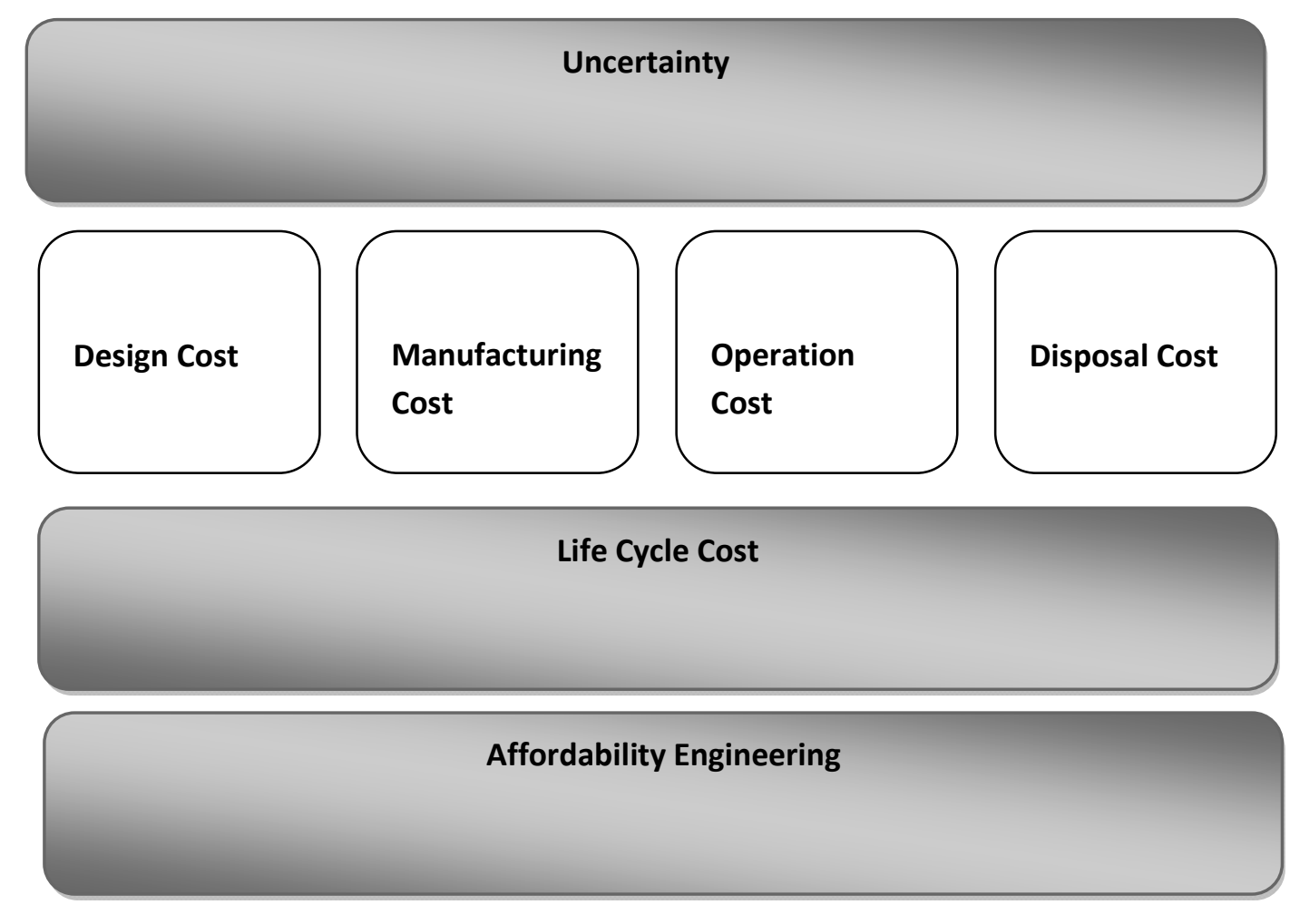

Figure 1. Key topics related to Cost Engineering

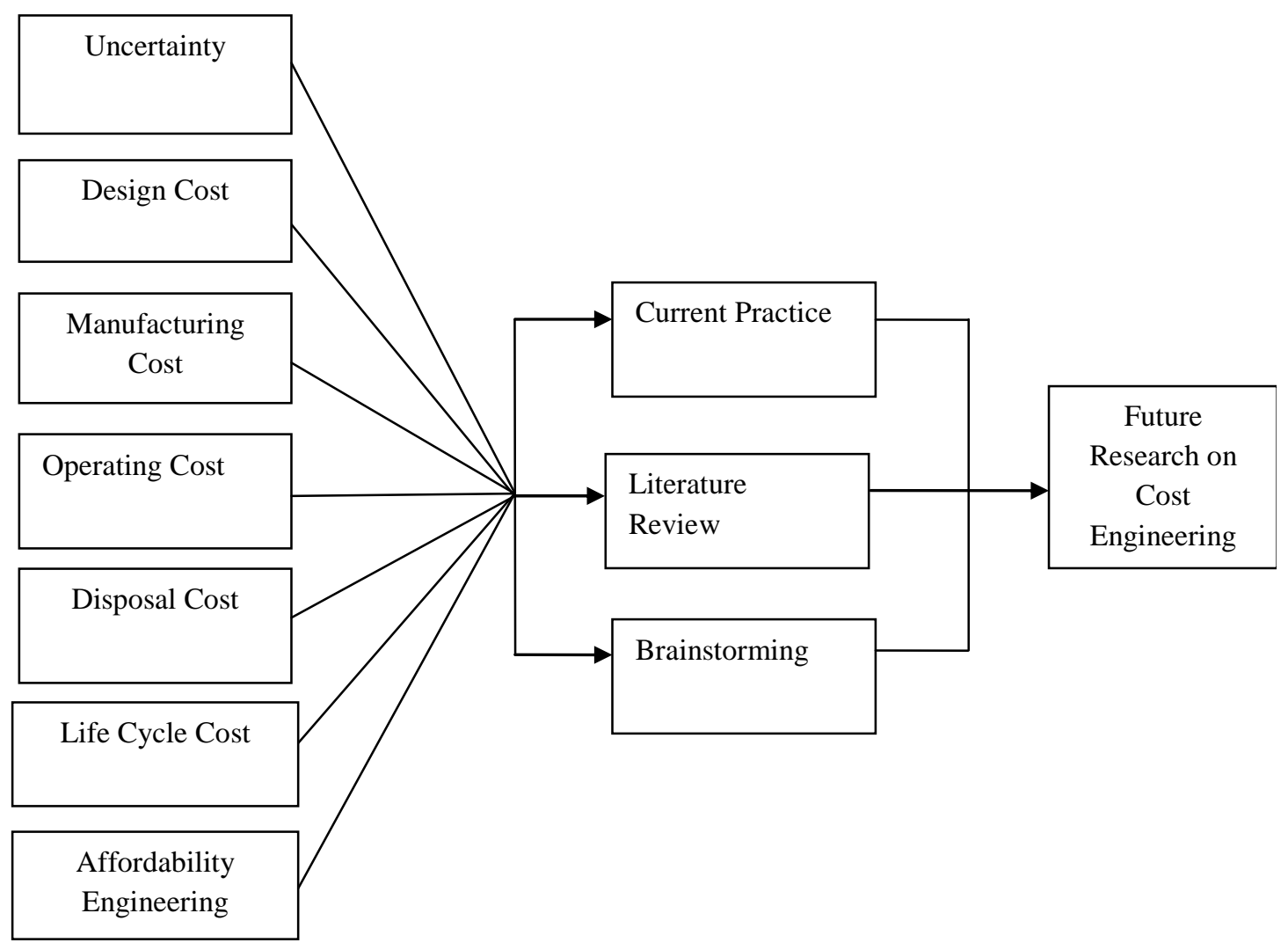

Figure 2. Adopted methodology 


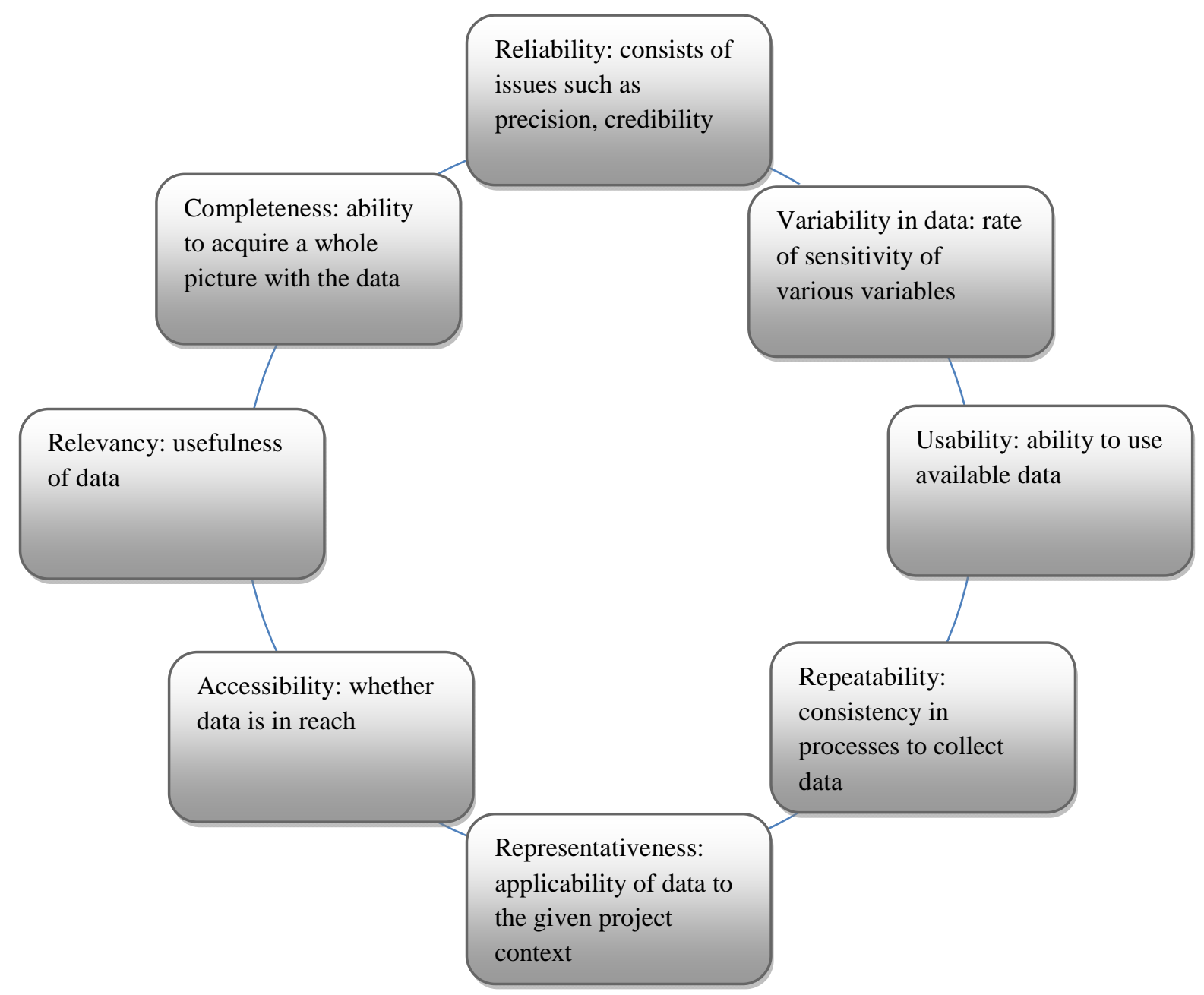

Figure 3. Data uncertainty

\section{COMMERCIAL FACTORS}

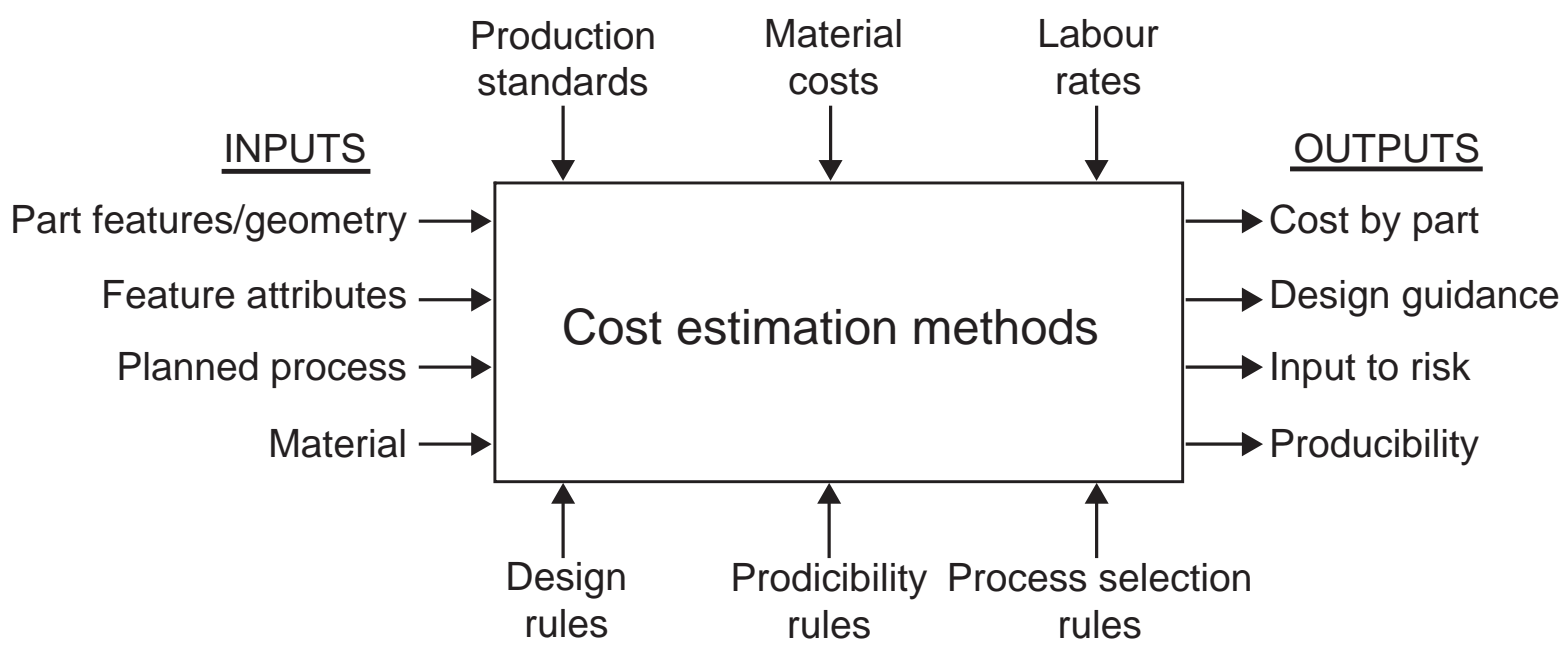

\section{RULES}

Figure 4. Required information for cost estimation with acceptable accuracy (Roy, 2003) 
Table 1. Approaches for operating cost estimation (Adapted from Boussabaine and Kirkham, 2004)

\begin{tabular}{|c|c|}
\hline Approach & Key characteristics \\
\hline Parametric model & $\begin{array}{l}\text { - Set of equations to relate Operating and Support (O\&S) costs to } \\
\text { parameters such as operating environment } \\
\text { - Used at the early stages of a project due to limited data }\end{array}$ \\
\hline Accounting Model & $\begin{array}{l}\text { - Set of equations to aggregate O\&S costs from simple relationships or } \\
\text { direct input }\end{array}$ \\
\hline Simulation Model & $\begin{array}{l}\text { - Computer simulation to determine effects on system characteristics, } \\
\text { operational constraints, maintenance plan, support requirements etc. } \\
\text { - Hardware parameters such as reliability, maintainability tend to be } \\
\text { - used } \\
\text { - Data requirements to generate probability density functions } \\
\text { Includes approaches such as system dynamics, discrete event and } \\
\text { Monte-Carlo }\end{array}$ \\
\hline
\end{tabular}

Table 2. Classification of uncertainties in cost data and models

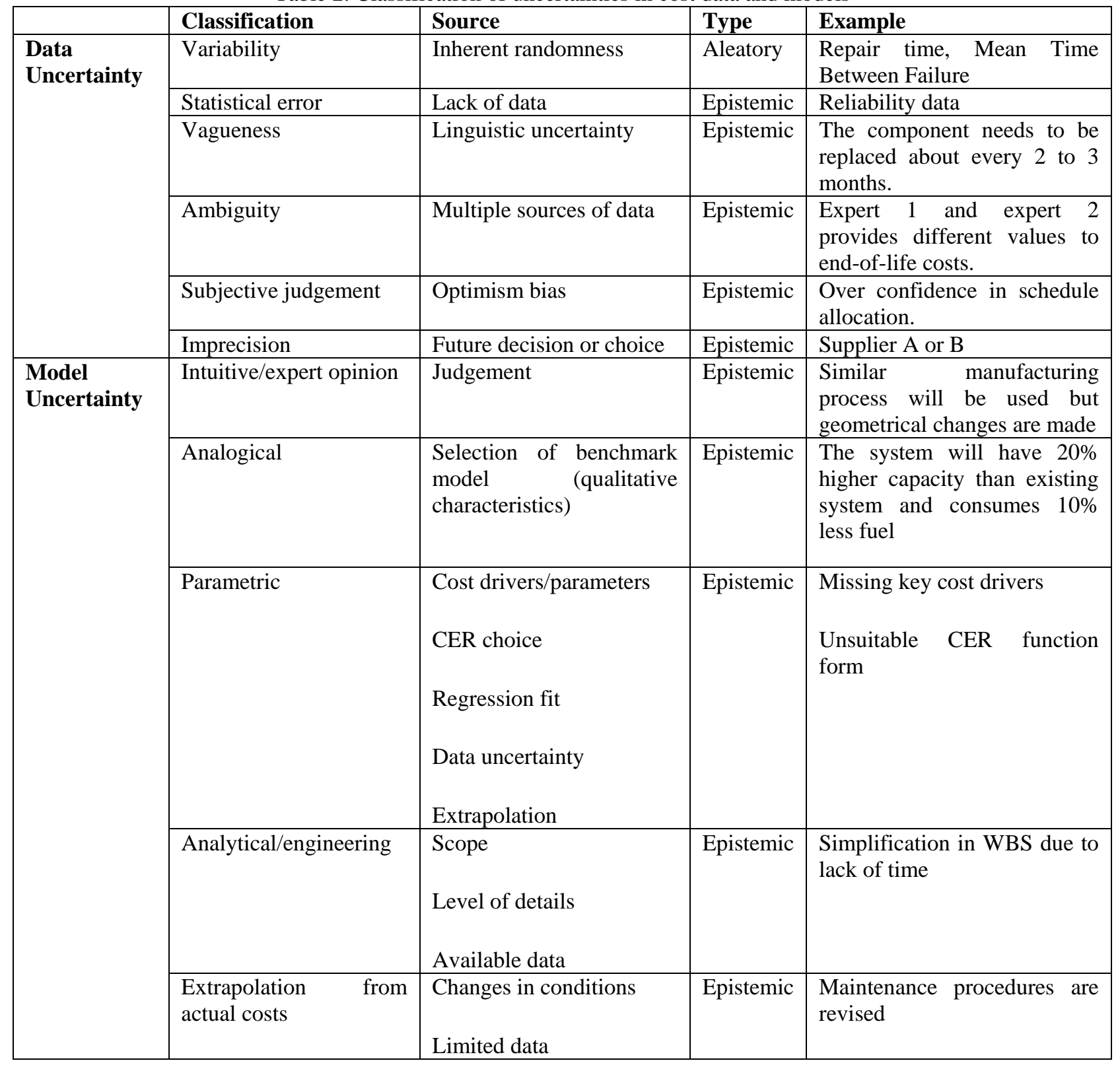

